BMJ Paediatrics Open

\title{
Incorporating parent, former patient and clinician perspectives in the design of a national UK double-cluster, randomised controlled trial addressing uncertainties in preterm nutrition
}

\author{
William Lammons (D) , ${ }^{1}$ Becky Moss, ${ }^{1}$ Cheryl Battersby (1) , ${ }^{2}$ Victoria Cornelius, ${ }^{3}$ \\ Daphne Babalis, ${ }^{3}$ Neena Modi ${ }^{1}$
}

To cite: Lammons W, Moss B, Battersby C, et al. Incorporating parent, former patient and clinician perspectives in the design of a national UK double-cluster, randomised controlled trial addressing uncertainties in preterm nutrition. BMJ Paediatrics Open 2021;5:e01112. doi:10.1136/ bmjpo-2021-001112

- Additional supplemental material is published online only. To view, please visit the journal online (http://dx.doi.org/ 10.1136/bmjpo-2021-001112).

Received 29 March 2021 Accepted 29 May 2021
Check for updates

(c) Author(s) (or their employer(s)) 2021. Re-use permitted under CC BY-NC. No commercial re-use. See rights and permissions. Published by BMJ.

${ }^{1}$ Section of Neonatal Medicine, Imperial College London, London, UK

${ }^{2}$ Neonatal Medicine, Imperial College London, London, UK ${ }^{3}$ Imperial Clinical Trials Unit, Imperial College London, London, UK

Correspondence to William Lammons; w.lammons@ imperial.ac.uk

\section{ABSTRACT}

Background Comparative effectiveness randomised controlled trials are powerful tools to resolve uncertainties in existing treatments and care processes. We sought parent and patient perspectives on the design of a planned national, double-cluster randomised controlled trial (COLLABORATE) to resolve two longstanding uncertainties in preterm nutrition.

Methods We used qualitative focus groups and interviews with parents, former patients and clinicians. We followed the Consolidated Criteria for Reporting Qualitative Research checklist and conducted framework analysis, a specific methodology within thematic analysis.

Results We identified support for the trial's methodology and vision, and elicited themes illustrating parents' emotional needs in relation to clinical research. These were: relieving the pressure on mothers to breastfeed; opt-out consent as reducing parent stress; the desire for research to be a partnership between clinicians, parents and researchers; the value of presenting trial information in a collaborative tone; and in a format that allows assimilation by parents at their own pace. We identified anxiety and cognitive dissonance among some clinicians in which they recognised the uncertainties that justify the trial but felt unable to participate because of their strongly held views.

Conclusions The early involvement of parents and former patients identified the centrality of parents' emotional needs in the design of comparative effectiveness research. These insights have been incorporated into trial enrolment processes and information provided to participants. Specific outputs were a two-sided leaflet providing very brief as well as more detailed information, and use of language that parents perceive as inclusive and participatory. Further work is warranted to support clinicians to address personal biases that inhibit trial participation.

\section{INTRODUCTION}

Many areas of neonatal practice lack an adequate evidence base; hence, treatments often vary, within and between centres. Comparative effectiveness research refers to

\section{What is known about the subject?}

Comparative effectiveness randomised controlled trials are powerful means of resolving uncertainties in existing treatments and care processes.

- Many areas of neonatal practice lack an adequate evidence base; hence, treatments often vary, within and between centres.

- The uncertainty around optimal practice creates risks for patients, anxiety for parents and confusion among staff.

\section{What this study adds?}

In addition to resolving practice uncertainties, comparative effectiveness research can help alleviate parent anxieties through metered study information, and partnership to improve newborn care.

- Early involvement of parents and former patients in trial development also enables researchers to support parents' emotional needs through appropriate recruitment materials and methods.

- Incorporating clinicians as stakeholders has potential to understand and address their personal biases that inhibit trial participation.

approaches to try and resolve uncertainties in established treatments.

COLLABORATE is a planned national, UK, double-cluster randomised controlled trial aiming to recruit at least 4700 babies to resolve two longstanding global uncertainties in preterm nutrition, the benefits of (1) pasteurised human donor milk in comparison with preterm formula to supplement a baby's own mother's milk when more milk is needed and (2) routine versus no routine protein-carbohydrate fortification of human milk. ${ }^{12}$ The coprimary outcomes are survival to 36 weeks postmenstrual age without 
surgery for necrotising enterocolitis (NEC) and survival to age 2 years without moderate-severe neurodevelopment impairment.

Currently in the UK less than $20 \%$ of very preterm babies receive any pasteurised donor milk and less than $40 \%$ receive any fortifier. ${ }^{3}$ The uncertainty around optimal practice creates risks for patients, anxiety for parents, and confusion among staff. COLLABORATE offers a pragmatic response to these uncertainties. COLLABORATE will use data from the National Neonatal Research Database to minimise clinical burden, ${ }^{4-6}$ and evaluate 2 year language and cognitive outcomes with a parentcompleted questionnaire, the Parent Report of Children's Abilities-Revised. ${ }^{7}$

These clinical uncertainties, which affect the care provided to babies as well as the information provided to families, present an opportunity to understand how parents of very preterm babies can improve the recruitment materials for the COLLABORATE trial and clarify the acceptability of consent methods, as well as compare their views and reactions with those of clinicians. PPI consultations are enriching mechanisms to improve design, making studies more successful and relevant to their stakeholders. ${ }^{8-12}$ In paediatric research, they have identified important guiding themes for future research, largely through centring the narratives and experiences of survivors and families. ${ }^{13} 14$ Our aim at this preliminary stage was to involve parents, former patients and clinicians in trial development.

\section{METHODS}

We recruited former neonatal intensive care patients and parents of patients from across the UK through a network of individuals with experience of preterm birth who had consented to be invited to participate in neonatal research activities. ${ }^{15}$ We invited the participation of healthcare professionals through a national webinar. In total, 20 volunteers $(10$ clinicians, 7 parents, 2 former patients, and 1 parent/former patient) participated in virtual focus groups or semistructured interviews. ${ }^{16} 17$ Sessions with single participants utilised the same topic guide. No clinicians attended the parent-patient groups to avoid inhibiting or influencing the discussions. ${ }^{16}{ }^{17}$ Participants gave verbal consent for participation and recording at the start of every discussion session.

We followed the Consolidated Criteria for Reporting Qualitative Research (COREQ) checklist for qualitative studies and created a topic guide to probe parent-patient and clinician experiences and understanding of the trial, based on a hybrid blend of deductive and inductive approaches to facilitate discussion and allow themes to emerge. ${ }^{18}{ }^{19}$ We provided a draft Parent Information Leaflet (online supplemental materials). Each session lasted approximately $90 \mathrm{~min}$, and all were recorded with participant consent. WL and BM, non-clinical qualitative researchers led the discussions and conducted interviews. They transcribed recordings and conducted interviews.
WL and BM analysed all qualitative data using framework analysis, a specific methodology within thematic analysis. ${ }^{20}$ Initial themes and concepts were identified through iterative review of the data, then used to construct a thematic index, or 'framework', and assign an index label to each phrase or passage of the transcripts. ${ }^{20}$ The indexed and labelled raw data were then summarised and synthesised into thematic charts to preserve the data's context while facilitating systematic exploration. These thematic charts produced salient themes, which serve as descriptive and explanatory accounts of the data. ${ }^{20}$ Data were organised and analysed using NVivo, V.1.0 (QSR International). ${ }^{21}$ Participants were provided contact information for psychological support services in the event that discussions elicited strong emotions.

\section{Patient and public involvement (PPI)}

At this preliminary stage of the development of COLLABORATE, we have used patient-public involvement to assist in developing the consent process and trial information leaflet. We have also involved clinicians to understand and address concerns related to their perspectives on opt-out consent, cluster randomisation and clinical uncertainties. This paper embodies the first phase of the study's public involvement strategy which includes parents, adults born preterm, and clinicians as research collaborators throughout the research cycle. ${ }^{22}$

\section{RESULTS}

Nine volunteers, all women (seven parents, one former patient, and one parent who is also a former patient) participated in parent-patient focus groups (table 1). Eleven volunteers for clinician focus groups included eight neonatologists, a dietician and an infant feeding specialist midwife. One non-clinician adult born preterm also chose to attend a clinician focus group. Seven of the eleven participants were men. No participant required the psychological support services that were offered.

We identified three parent-patient themes; 'pressure to breastfeed', 'consent process', and 'emotional trauma'; one clinician theme, 'equipoise and personal beliefs'; and one theme combining parent-patient and clinician discussions, 'collaboration and inclusivity.'

\section{Theme 1 pressure to breastfeed}

Participants almost universally cited the refrain, 'breast is best,' but mothers' experiences of expressing milk and breast feeding provoked stress and feelings of inadequacy. One former patient articulated the challenges of breastfeeding with an anecdote from her own mother:

'...my mum will share with me that she cried with her breasts bleeding, trying to express because she was told it was the best... And she had a woman sitting next to her in the expressing room who had, you know, 500 mils of milk sitting there... and this woman was saying, 'Oh, it's not enough.' My 
Table 1 Parent and patient participant characteristics 1

\begin{tabular}{|c|c|c|c|c|c|c|c|}
\hline Participant & $\begin{array}{l}\text { Gestational } \\
\text { age of child or } \\
\text { patient }\end{array}$ & $\begin{array}{l}\text { Reason for interest } \\
\text { in participating }\end{array}$ & $\begin{array}{l}\text { Feeding } \\
\text { method }\end{array}$ & $\begin{array}{l}\text { Single/multiple } \\
\text { birth }\end{array}$ & $\begin{array}{l}\text { Incidence of } \\
\text { necrotising } \\
\text { enterocolitis (NEC)? }\end{array}$ & $\begin{array}{l}\text { Survival of } \\
\text { baby(ies) }\end{array}$ & $\begin{array}{l}\text { Support } \\
\text { for trial }\end{array}$ \\
\hline Parent 1 & $33+3$ weeks & $\begin{array}{l}\text { Pharmacist w/RCT } \\
\text { experience }\end{array}$ & Mum's milk & Single & $\mathrm{N}$ & $\mathrm{Y}$ & $\mathrm{Y}$ \\
\hline Parent 2 & $n / a$ & $\begin{array}{l}\mathrm{NEC} / \text { preterm charity } \\
\text { volunteer }\end{array}$ & $\begin{array}{l}\text { Mum's milk and } \\
\text { formula }\end{array}$ & Single & $\mathrm{Y}$ & $\mathrm{Y}$ & $\mathrm{N}$ \\
\hline Parent 4 & 22 weeks & $\begin{array}{l}\text { NEC/preterm charity } \\
\text { volunteer }\end{array}$ & $\begin{array}{l}\text { Mum's milk and } \\
\text { donor milk }\end{array}$ & Twins & $\mathrm{N} / \mathrm{N}$ & $\mathrm{Y} / \mathrm{N}$ & $\mathrm{Y}$ \\
\hline Parent 5 & 33 weeks & $\mathrm{n} / \mathrm{a}$ & $\begin{array}{l}\text { Mum's milk and } \\
\text { fortifier }\end{array}$ & Single & $\mathrm{Y}$ & $\mathrm{N}$ & Unsure \\
\hline Parent 6 & $29+5$ weeks & $n / a$ & $\begin{array}{l}\text { Mum's milk and } \\
\text { formula }\end{array}$ & Twins & Suspected NEC/N & $\mathrm{Y} / \mathrm{Y}$ & $\mathrm{Y}$ \\
\hline Patient 1 & $28+4$ weeks & Paediatric nurse & $\begin{array}{l}\text { Mum's milk and } \\
\text { Formula }\end{array}$ & Twin & N/suspected NEC & Y/N3 & Y \\
\hline
\end{tabular}

mum was like, 'you're kidding me. I've got five ml from the last four hours. And I'm bleeding into it.' (NICU patient born at $28+4$ weeks, now a paediatric nurse)

Parents showed understanding of the trial's aim of resolving feeding uncertainties. The discussion identified confusion around feeding options that were brought to the fore by the challenges of expressing sufficient milk.

'I remember when they talked about putting him onto formula, I said to the consultant, 'I'm really, really worried about him getting NEC [necrotising enterocolitis]. I'm really worried.' Cause I had it and...I know how bad it is...they assured me that the risk with formula was just as high as it was with donor milk. So I was like...if they need to gain weight and it's such a balancing act, isn't it?...I suppose it's the same for the doctors. They're just trying to balance the best options.' (Mother who had NEC as a preterm baby, whose baby was born at 29 weeks)

Participants emphasised sensitivity was needed to support mothers when discussing feeding.

'... And at the end of the day, it has to be what's best... for your circumstances and what's best for your baby because your mum's milk is best, but if mum's milk is not available... you shouldn't make mums feel as if they're kind of a failure.' (Mother of twins born at $29+5$ weeks)

\section{Theme 2 consent process}

Parent-patient participants and most clinicians supported opt-out as minimising the added stress of trial consent in an already stressful environment. One parent stated

'...I appreciate the opt-out allows a much larger number of people, and often families don't go there. Not because they don't necessarily want to do it, but for whatever reason they have...they're not thinking about it or they read [the consent form]....and forget to fill out...' (Mother of a preterm baby who had NEG)

Other participants echoed this sentiment noting that usual trial consent and information processes are often cumbersome and confusing. Some clinicians went further, suggesting that cluster randomisation meant that opt-out consent was required only from a neonatal unit rather than from parents themselves.

However, worries around transparency led some clinicians to feel uncomfortable with opt-out consent. For example, one told us they felt opt-out was only appropriate when a rapid decision was needed for a timecritical intervention.

\section{Theme 3 collaboration and inclusivity}

Parent-patient participants emphasised the confusion and anxiety that results from lack of clarity or consistency in medical information communicated to them. They felt researchers can help alleviate these anxieties through the tone they adopt as well as the clarity of their communications. 
'They need to be able to sometimes slightly dumb it down so we can understand it really well... I'm focusing on 'add extra protein and carbohydrate' [in the parent information leaflet.] I've never heard of that before...' (Mother of twin boys born at 22 weeks, one of whom did not survive)

They recommended we remove phrases in the draft parent information leaflet such as 'if a mother has insufficient milk' (online supplemental materials). They encouraged general use of words and phrases that expressed empathy for mothers' difficulties as opposed to ones that provoked feelings of guilt or inadequacy, supportive of an 'inclusive' tone.

'The document, as it reads, is looking to me like dumbed down 'science-y' stuff. Whereas I think it needs to come from a person to person, like where you have concerns and fears, and this is what we are trying to do together as a community of NICU [neonatal intensive care unit] survivors and clinicians...' (Mother of twin boys born at 22 weeks, one of whom did not survive)

This parent's reference to a 'community of survivors' illustrates their need for empathy.

Clinician participants recognised the importance of fostering a collaborative relationship with parents:

'I think this whole thing about us having to approach parents in a really collaborative way around the importance of...feeding...managing their expectations and their understanding of what is happening with that baby's gut, and that we're trying to help promote a healthy gut, not just for the time when they're in their unit, but beyond that time as a healthy gut for life-here is the one of the fundamental things that's going to influence their feeding for not just weeks, but months and years to come.' (Neonatal clinician)

They perceived a tension between ensuring information was shared transparently and managing parental anxiety. Offering clear and consistent explanations was seen as paramount, but this was sometimes difficult because of clinical uncertainties and professional differences of opinion.

\section{Theme 4 trauma, powerlessness, and parental learning in the neonatal unit}

Mothers experienced trauma and feelings of powerlessness, when their babies were 'taken away' for intensive care almost immediately following birth.

'...I had this baby ripped from me...I didn't see her after birth. It was horrific...her first nappy was changed by somebody else... All her cares were done by somebody else. The first person she saw was somebody else' (Mother of a preterm baby with NEG)
A lack of knowledge of neonatal care typically amplified these emotional experiences and participants described feelings of urgency to obtain more information.

... when you're in hospital and you've just had a new baby, especially if the baby's premature and you just have...so little time...' (Mother of a baby born at $33+3$ weeks, pharmacist)

At the same time, often, you do have a lot of time to kill in the neonatal unit ... you will read every leaflet front to back' (Mother of a preterm baby)

Pursuing knowledge helped remedy feelings of powerlessness for some mothers, though a broader awareness of dangers facing babies often increased anxiety for others.

'I'm the sort of person that likes to know everything, so I would want to read every tiny little detail of everything...but I know from speaking to other parents in the neonatal unit that a lot of parents...don't want to be involved as much and they don't want to know things. (Mother of a preterm baby who had NEG)'

In summary, parents reported varying degrees of desire for knowledge, from those who wanted to know 'everything' and those who wanted a more general understanding.

\section{Theme 5: equipoise and personal beliefs}

Clinicians described the difficulty of managing their own anxieties about treatments in discussions with parents to minimise parent feelings of emotional distress and ensure equipoise across the unit.

'On a ward round, one negative sentence, a loose comment about something ... just spoils everything. We try to police that to some extent [and] share all our anxieties and disagreement beforehand ....we have our own personal agendas or personal biases but keep them to ourselves when we are ... in front of other people. That's where I see the issue about [a] unit that's sort of consenting to participate, but not then sticking to the protocol... and then bringing some of their own ideas into the consenting ... [and] recruitment process.' (Neonatal clinician)

Clinicians identified that the anxieties, disagreements, and biases that are common to care could amount to complications in trial procedures for some units. Despite broad acceptance of the need for a trial, many clinicians predicted neonatal units with a standardised feeding regimen would not agree to change them and would therefore decline to participate. Clinical focus group participants accepted the existence of clinical uncertainties and understood the need for a definitive trial. For example, one said: 
'We've been asking these questions for so long and we still haven't got the answer' (Neonatal clinician)

\section{DISCUSSION}

This PPI consultation with parent, former patient and clinician views about a planned national double-cluster randomised controlled trial involved participants with intimate knowledge of neonatal care, and the corresponding relevance and depth of their contributions provide novel insights. We identified support for the rationale and proposed methodology, and themes within and across groups. Particularly powerful themes related to the emotional needs of parents and the personal beliefs of clinicians. Parents experience stress and anxiety because of their baby's admission to intensive care. A novel insight provided by this consultation is that comparative effectiveness research might help alleviate parent anxieties in several ways. Clinician participants identified anxieties arising from the tension between their personal views and their acknowledgement of the need for evidence to guide practice. The methodology around PPI consultations continues to evolve. ${ }^{23}$ Utilising PPI consultations in a study's early stages can assure relevance for patients and parents in the study's recruitment methods, ethics application, research protocol, and outcomes. ${ }^{8}$ Our group illustrated an example of PPI consultations to identify a core outcome set for neonatology through consensus meetings around stakeholder viewpoints. ${ }^{4}$ Others have called for 'integration' of parents in research by frequently inviting their feedback. ${ }^{14}$

Participants voiced support for the use of opt-out consent, noting it reduced the anxiety of decisionmaking. Some authors have criticised opt-out consent as not supporting informed consent. ${ }^{24}$ However, the stress of neonatal intensive care complicates parent understanding of studies. ${ }^{25}$ Our group has previously shown opt-out taps 'into parents' desire for normality in an abnormal situation' ${ }^{26}$ We have also shown that opt-out, as with opt-in consent, can be viewed as an ongoing consent process, leaving parents able to withdraw participation at any time, and that this approach is acceptable to the UK National Research Ethics Service. ${ }^{27}$ Opt-out also allows parents to understand the trial and decline to participate without imposing a burden of additional information processing. ${ }^{26}$

The insights provided by consultation participants indicated the Parent Information Leaflet could be structured to provide emotional assistance by minimising the anxiety provoked by varying desires for information. This could be achieved by presenting information in a collaborative tone that situates the research as a partnership between clinicians, parents and researchers, and employing a format that allows parents to assimilate information at their own pace. The language used can also help avoid making mothers feel inadequate by recognising the challenges of providing milk for their babies and alleviating the pressure to breastfeed. Our participants advised metering trial information to accommodate the needs of parents who want only a small amount of information as well as those who want to know more. The rationale for comparative effectiveness research is the relevance to patient safety of resolving uncertainties in care. However, 'uncertain' does not necessarily describe how parents experience the moment of selecting a nutritional option. What is 'uncertain' in terms of clinical practice is experienced as 'worry', guilt and even trauma by parents. This stems from a mixture of a shortfall in knowledge and the requirement to process substantial new information. The information provided through research participation enables parents to understand the issues facing their babies, providing direct benefit and a safe space to learn about neonatal treatments. As a consequence of these insights we undertook a redesign of the information leaflet to allow parents to adjust how much information they would receive by converting it into a two-sided format with a very brief explanation of the study on the front and a more detailed explanation on the back (online supplemental materials).

We identified anxiety among clinicians that manifest as a strong tendency to focus on the detail of the trial rather than the bigger picture even though the trial compares standard clinical practices. The main driver of anxiety was difficulty in managing uncertainty, both in terms of explaining this to parents and in accommodating it in their own practice. We found a cognitive dissonance at play, whereby the rationale for the trial is acceptable, yet involvement and being forced to confront their own personal views and biases led many to reject participation. In contrast, parents and patients felt that the proposed trial helped allay the anxieties invoked by the very uncertainties that justified the trial.

Our research has identified important areas for incorporation into the design of COLLABORATE and other comparative-effectiveness studies. Participating in research provides parents with a forum in which to learn about neonatal treatments, participate in knowledge production, and shape future care. Furthermore, in addition to the baby's medical care needs, this consultation, along with others, has identified that the provision of information to participants and enrolment to trials should consider the emotional needs of the parents as affected by study decision-making, information processing and language in study materials. ${ }^{28}{ }^{29}$ This consultation illustrates the need for further work to address the anxieties described and experienced by healthcare professionals. We hope this will help spearhead a truly collaborative research culture between parents, clinicians, and researchers.

Twitter William Lammons @william_lammons and Cheryl Battersby @cwsbattersby Acknowledgements We would like to thank Saulius Satas, Juliette Lee, Sara Clarke, Nadia Leake, Shalabh Garg, Nicola Pritchard, Ganka Taneva and also the other parents, adults born preterm, and clinicians who participated in this PPI consultation for the COLLABORATE trial. 
Contributors All authors contributed to the research design of the parent, patient, and public involvement, qualitative methods, the revision of this manuscript, approval of the final draft for publication, and responsibility for the intellectual content within. Specific specialisations are described below. WL: writing, draft editing, thematic analysis, qualitative design, public involvement design and data collection. BM: writing, draft editing, thematic analysis, qualitative design, public involvement design and data collection. CB: writing, draft editing, qualitative participant recruitment. VC: writing, draft editing, randomised controlled trial (RCT) design. DB: writing, draft editing, RCT design. NM: writing, draft editing, qualitative design, public involvement design, RCT design.

Funding The authors have not declared a specific grant for this research from any funding agency in the public, commercial or not-for-profit sectors.

Competing interests $\mathrm{CB}$ reports grants and personal awards funded by the NIHR, NM reports grants from Medical Research Council, grants from National Institute for Health Research, grants from Prolacta Life Sciences, grants from Chiesi International, grants from Westminster Children's Research Trust, grants from European Health Data and Evidence Network, grants from HCA International, grants from Health Data Research UK, grants from Shire Pharmaceuticals, grants from March of Dimes, outside the submitted work; CB is deputy chair of the NIHR Health Technology Assessment Prioritisation Committee for Hospital based care, NM is a member of the Nestle International Scientific Advisory Board (accepts no personal remuneration for this role).

Patient consent for publication Not required.

Ethics approval Research ethics approval for PPI consultations is not required. ${ }^{9}$ However, we approached parents and former patients through the neoWONDER group that had agreed to be invited to participate in consultations (REC reference: 20/yh/0330).

Provenance and peer review Not commissioned; externally peer reviewed.

Data availability statement Data are available upon reasonable request. All data relevant to the study are included in the article or uploaded as supplementary information. Further anonymised data are available upon request from the corresponding author.

Supplemental material This content has been supplied by the author(s). It has not been vetted by BMJ Publishing Group Limited (BMJ) and may not have been peer-reviewed. Any opinions or recommendations discussed are solely those of the author(s) and are not endorsed by BMJ. BMJ disclaims all liability and responsibility arising from any reliance placed on the content. Where the content includes any translated material, BMJ does not warrant the accuracy and reliability of the translations (including but not limited to local regulations, clinical guidelines, terminology, drug names and drug dosages), and is not responsible for any error and/or omissions arising from translation and adaptation or otherwise.

Open access This is an open access article distributed in accordance with the Creative Commons Attribution Non Commercial (CC BY-NC 4.0) license, which permits others to distribute, remix, adapt, build upon this work non-commercially, and license their derivative works on different terms, provided the original work is properly cited, appropriate credit is given, any changes made indicated, and the use is non-commercial. See: http://creativecommons.org/licenses/by-nc/4.0/.

ORCID iDs

William Lammons http://orcid.org/0000-0002-8302-9831

Cheryl Battersby http://orcid.org/0000-0002-2898-553X

\section{REFERENCES}

1 McGuire W, Quigley M, Embleton N. Formula versus donor breast milk for feeding preterm or low birth weight infants. Cochrane Database of Systematic Reviews 2019;6:1-65.

2 Brown J, Lin L, Embleton N. Multi-nutrient fortification of human milk for preterm infants. Cochrane Database of Systematic Reviews 2013;6:1-64.

3 Greenbury SF, Ougham K, Wu J, et al. Identification of variation in nutritional practice in neonatal units in England and association with clinical outcomes using agnostic machine learning. Sci Rep 2021;11:7178.

4 Webbe JWH, Duffy JMN, Afonso E, et al. Core outcomes in neonatology: development of a core outcome set for neonatal research. Arch Dis Child Fetal Neonatal Ed 2020;105:425-31.

5 Modi N, Ashby D, Battersby C, et al. Developing routinely recorded clinical data from electronic patient records as a national resource to improve neonatal health care: the medicines for neonates research programme. Programme Grants for Applied Research 2019;7:1-396.

6 Modi N. Information technology infrastructure, quality improvement and research: the UK national neonatal research database. Trans/ Pediatr 2019:8:193-8.

7 Johnson S, Bountziouka V, Brocklehurst P, et al. Standardisation of the parent report of children's Abilities-Revised (PARCA-R): a normreferenced assessment of cognitive and language development at age 2 years. Lancet Child Adolesc Health 2019;3:705-12.

8 Fiori M, Endacott R, Latour JM. Public involvement in designing a study on patient-witnessed cardiopulmonary resuscitation in hospital. Nurs Crit Care 2020;25:313-20.

9 INVOLVE, NIHR. Patient and public involvement in research and research ethics Committee review. NIHR. version 1. 2009. Available: https://www.invo.org.uk/wp-content/uploads/2011/12/INVOLVEN RESfinalStatement310309.pdf [Accessed May 2021].

10 INVOLVE, NIHR (National Institute of Health Research). Public involvement in research: impact on ethical aspects of research, 2014. Available: www.involve.nihr.ac.uk [Accessed May 2021].

11 Bliss: for babies born premature or sick. our approach to research. Available: https://www.bliss.org.uk/research-campaigns/research [Accessed May 2021].

12 National Institute for Health Research. Patient and public involvement in health and social care research: a Handbook for researchers by. London: Research Design Service, 2014: 1-40. http://www.rds.nihr.ac.uk/wp-content/uploads/RDS-PPI-Handbook2014-v8-FINAL.pdf;

13 Manning JC, Hemingway P, Redsell SA. Survived so what? identifying priorities for research with children and families postpaediatric intensive care unit. Nurs Crit Care 2018;23:68-74.

14 Janvier A, Bourque CJ, Dahan S, et al. Integrating parents in neonatal and pediatric research. Neonatology 2019;115:283-91.

15 NeoWONDER: neonatal whole population data linkage to improve lifelong health and wellbeing of preterm babies 2020. Available: https://www.neowonder.org.uk/ [Accessed Feb 2021]

16 Finch H, Lewis J. Focus Groups. In: Ritchie J, Lewis J, eds. Qualitative research practice: a guide for social science students and researchers. Thousand Oaks, CA: Sage Publications, 2003: 170-98.

17 Barbour RS, Schostak J. Interviewing and Focus Groups. In: Somekh B, Lewin C, eds. Research methods in the social sciences. Thousand Oaks, CA: Sage Publications, 2005: 41-8.

18 Tong A, Sainsbury P, Craig J. Consolidated criteria for reporting qualitative research (COREQ): a 32-item checklist for interviews and focus groups. Int J Qual Health Care 2007;19:349-57.

19 Fereday J, Muir-Cochrane E. Demonstrating rigor using thematic analysis: a hybrid approach of inductive and deductive coding and theme development. Int J Qual Methods 2006;5:80-92.

20 Ritchie J, Spencer L, O'Connor W. "Carrying out Qualitative Analysis". In: Ritchie J, Lewis J, eds. Qualitative research practice: a guide for social science students and researchers. Thousand Oaks, CA: Sage Publications, 2003: 170-98.

21 QSR international Pty Ltd. NVivo, 2020. Available: https://www. qsrinternational.com/nvivo-qualitative-data-analysis-software/home

22 Greenhalgh T, Hinton L, Finlay T, et al. Frameworks for supporting patient and public involvement in research: systematic review and co-design pilot. Health Expect 2019;22:785-801.

23 Ocloo J, Matthews R. From tokenism to empowerment: progressing patient and public involvement in healthcare improvement. BMJ Qual Saf 2016;25:626-32.

24 Berry JG, Ryan P, Duszynski KM, et al. Parent perspectives on consent for the linkage of data to evaluate vaccine safety: a randomised trial of opt-in and opt-out consent. Clin Trials 2013;10:483-94

25 Mason SA, Allmark PJ. Obtaining informed consent to neonatal randomised controlled trials: interviews with parents and clinicians in the Euricon study. Lancet 2000;356:2045-51.

26 McLeish J, Alderdice F, Robberts $\mathrm{H}$, et al. Challenges of a simplified opt-out consent process in a neonatal randomised controlled trial: qualitative study of parents' and health professionals' views and experiences. Arch Dis Child Fetal Neonatal Ed 2021;106:244-50.

27 Gale C, Hyde MJ, Modi N, et al. Research ethics Committee decision-making in relation to an efficient neonatal trial. Arch Dis Child Fetal Neonatal Ed 2017;102:F291-8.

28 Neu M, Klawetter S, Greenfield JC, et al. Mothers' experiences in the NICU before Family-Centered care and in NICUs where it is the standard of care. Adv Neonatal Care 2020;20:68-79.

29 Mörelius E, Kling K, Haraldsson E, Eva RN, et al. You can't flight, you need to fight-A qualitative study of mothers' experiences of feeding extremely preterm infants. J Clin Nurs 2020;29:2420-8. 